\title{
Keragaan Nilai DO, BOD dan COD di Danau Bekas Tambang Batu bara Studi Kasus pada Danau Sangatta North PT. KPC di Kalimatan Timur
}

\author{
Behavior of DO, BOD and COD Value at Coal Mine Void \\ Case study in Sangatta North Lake PT. KPC in The East Kalimantan
}

\author{
ARIF DWI SANTOSO \\ Pusat Teknologi Lingkungan, Badan Pengkajian dan Penerapan Teknologi \\ Gedung 820 Geostek, Kawasan Puspiptek Serpong, Tangerang Selatan \\ arif.dwi@bppt.go.id
}

\begin{abstract}
One of the main wastes of the coal industry is water from production processes of coal mine wastewater that collect in the artificial lake was dissolving rocks and oxidation process from waste mining material so that potentially produce acid mine water containing unwanted materials and harmful to the environment. It is necessary to identify the water quality of the lake so that it can be known the design of its conservation. The purpose of this paper is to describe the existing condition of water quality at the artificial lake, especially BOD (biological oxygen dissolved) and COD (chemical oxygen demand) and other supporting parameters. To achieve these objectives, a survey of measurements of pond depth, temperature, $\mathrm{pH}$, oxygen dissolved (DO), and chlorophyll content was performed using a multi-parameter sensor probe (Chlorotec, type AAQ1183, Alec Electronics), and sampled at 3 stations for known BOD and COD data. The result of data analysis showed that BOD, COD lake values ranged from 2- $5.57 \mathrm{mg} / \mathrm{l}$. This value is supported by the value of $D O$ parameters and a relatively good $\mathrm{pH}$. The $D O$ value is about 2.8-6.89 (4.71 $\pm 1.28) \mathrm{mg} / \mathrm{l}$ and the $\mathrm{pH}$ value is about $6-7.8$ (7.1 \pm 0.55$)$. In general, the water in Sangatta North Lake is stable and normal so that it can be used for water recreation, freshwater fish farming, farming, irrigation of agriculture and other designations that require water quality in class II.
\end{abstract}

Keywords: BOD (biological oxygen dissolved), COD (chemical oxygen demand), coal former lake, DO (dissolved oxygen).

\begin{abstract}
ABSTRAK
Salah satu limbah utama dari industri batu bara adalah air dari proses produksi dan aktivitas lain yang ditampung dalam danau buatan. Air limbah dalam danau buatan ini mengalami pelarutan batuan dan proses oksidasi dari material sisa penambangan sehingga berpotensi menghasilkan air asam tambang yang mengandung bahan-bahan yang tidak diinginkan dan berbahaya bagi lingkungan. Untuk memanfaatkan air bekas tambang tersebut perlu dilakukan identifikasi kualitas air danau sehingga dapat diketahui perancangan konservasinya. Tujuan paper ini ingin memaparkan kondisi eksisting kualitas air bekas tambang, khususnya nilai BOD (biological oxygen dissolved) dan COD (chemical oxygen demand) serta parameter penunjang lainnya. Untuk mencapai tujuan tersebut, telah dilakukan survei pengukuran data kedalaman kolam, temperatur, $\mathrm{pH}$, oksigen terlarut (DO), dan kandungan klorofil a secara langsung dengan menggunakan probe sensor multi parameter (Chlorotec, type AAQ1183, Alec Electronics), serta mengambil sampel di 11 stasiun untuk diketahui data BOD dan COD. Hasil analisis data menunjukkan Nilai BOD, COD danau berkisar 2 dan $5,57 \mathrm{mg} / \mathrm{l}$. Nilai ini ditunjang oleh nilai parameter DO dan $\mathrm{pH}$ yang relatif baik. Nilai DO sekitar 2,8-6,89 $(4,71 \pm 1.28) \mathrm{mg} / \mathrm{l}$ dan nilai pH sekitar $6-7,8(7,1 \pm 0,55)$. Secara umum air pada danau Sangatta North dalam kondisi stabil dan normal sehingga dapat dimanfaatkan untuk kepentingan sarana rekreasi air, pembudidayaan ikan air tawar, peternakan, pengairan pertanian dan peruntukan lain yang mempersyaratkan mutu air pada kelas II.
\end{abstract}

Kata kunci: BOD (biological oxygen dissolved), COD (chemical oxygen demand), danau bekas batu bara, DO (dissolved oxygen) 


\section{PENDAHULUAN}

\subsection{Latar Belakang}

Batu bara adalah salah satu bahan tambang sebagai sumber energi terpenting untuk pembangkitan listrik dan berfungsi sebagai bahan bakar pokok untuk produksi baja dan semen ${ }^{(1)}$. Indonesia adalah salah satu produsen dan eksportir batu bara terbesar di dunia dengan menempati peringkat ke-9 dengan sekitar 2.2 persen dari total cadangan batu bara global(2). Industri batu bara memiliki karakter negatif sebagai sumber energi yang paling banyak menimbulkan polusi akibat tingginya kandungan karbon dan pada proses produksinya memerlukan dan menghasillkan limbah air yang ditampung pada kolam/danau buatan ${ }^{(3)}$. Danau buatan bekas tambang batu bara merupakan wilayah cekungan yang sengaja dibuat dan digunakan sebagai wadah penampungan air limbah dari aktivitas pertambangan. Dari sisi limnologi, danau buatan ini memiliki 2 sisi peluang yang harus diketahui oleh pengelola danau. Sisi pertama adalah akumulasi air limbah dari aktivitas penambangan dan rehabilitasi lahan pasca tambang akan mengakibatkan terjadinya perubahan struktur batuan yang diikuti dengan perubahan kualitas fisika dan kimia tanah serta air di sekitarnya ${ }^{(4)}$. Hal ini terjadi akibat adanya pelarutan batuan dan proses oksidasi dari material sisa penambangan yang akan menghasilkan air asam tambang yang mengandung bahan-bahan yang tidak diinginkan dan berbahaya bagi lingkungan ${ }^{(5)}$. Bila air asam tambang ini dibuang begitu saja ke lingkungan, maka akan berpotensi menyebabkan terjadinya pencemaran yang mengganggu keseimbangan proses-proses self recovery yang ada di dalam danau tersebut ${ }^{(6)}$. Pada sisi lain, danau buatan merupakan salah satu sumberdaya alam yang sangat vital, terkait dengan ketersediaan air yang dapat dimanfaatkan oleh manusia dan mahluk hidup di sekelilingnya ${ }^{(7,8)}$.

Dalam upaya untuk memanfaatkan air limbah dari industri batu bara, maka diperlukan upaya untuk menjaga kualitas air danau agar dalam keadaan baik. Air danau dikatakan baik apabila air tersebut dapat digunakan sesuai dengan peruntukannya, kondisi air tidak terkontaminasi oleh material atau partikel, atau zat lain yang dapat menyebabkan kualitas air tidak dapat lagi mendukung kehidupan biota yang ada di dalamnya ${ }^{(9,10)}$

Beberapa parameter yang sering dikaitkan dengan kondisi produktivitas perairan termasuk danau adalah paremeter BOD (biological oxygen dissolved) dan COD (chemical oxygen demand) (11). Dengan mengetahui aktivitas biologi pada air danau dalam nilai BOD dan COD, akan dapat diketahui status kualitas danau sehingga menjadi rujukan bagai pengelola danau untuk menentukan metode penanganannya sehingga menjadikan fungsi danau lebih bermanfaat.

\subsection{Studi Pustaka}

\section{Kondisi BOD dan COD Danau Bekas Tambang Batu Bara}

Danau bekas tambang batu bara merupakan cekungan yang sengaja dikonstruksi untuk menambung limbah air dari kegiatan produksi tambang batu bara dan limbah kegiatan lainnya. Kondisi air pada danau ini bersifat asam, akibat dari terbentuknya air asam tambang dari proses produksi tambang batu bara. Air asam tambang ini terbentuk karena adanya oksidasi beberapa mineral besi dan sulfide logam seperti $\mathrm{FeS}_{2}$ (pyrite), $\mathrm{Fe}_{\mathrm{x}} \mathrm{S}_{\mathrm{x}}$ (pyrrhotite), PbS (galena), CuS (chalco-cite), CuS (covellite), $\mathrm{CuFeS}_{2}$ (chalcopyrite), MoS (molybdenite), NiS (millerite), ZnS (sphalerite), dan $\mathrm{FeAsS}_{2}$ (arsenopyrite). Dengan adanya kandungan air asam ini, biasanya air danau bekas batu bara memiliki $\mathrm{pH}$ yang rendah $<3-4)^{(11)}$. Rendahnya $\mathrm{pH}$ ini secara tidak langsung akan mempengaruhi nilai $\mathrm{BOD}$ dan COD danau secara signifikan. Nilai BOD dan COD danau bekas batu bara sekitar $5 \mathrm{mg} / \mathrm{L}$ dan 26-32 mg/L ${ }^{(12)}$. Nilai BOD dan COD ini jauh di bawah batas yang ditetapkan oleh baku mutu.

\section{Pengertian BOD dan Metode Pengukurannya}

BOD atau Biochemical Oxygen Demand adalah suatu jumlah oksigen terlarut yang diperlukan oleh mikroorganisme (biasanya bakteri) untuk mengurai atau mendekomposisi bahan organik dalam kondisi aerobik ${ }^{(13,14,15)}$. BOD sebagai suatu ukuran jumlah oksigen yang digunakan oleh populasi mikroba yang terkandung dalam perairan sebagai respon terhadap masuknya bahan organik yang dapat diurai. Beberapa peneliti menambahkan bahwa pengertian $\mathrm{BOD}$ tidak hanya menyatakan jumlah oksigen, tetapi juga menyatakan jumlah bahan organik mudah urai (biodegradable organics) yang ada di perairan ${ }^{(16)}$.

Metode pengukuran BOD cukup sederhana, yaitu mengukur kandungan oksigen terlarut awal $(\mathrm{DO} I)$ dari sampel pada awal pengambilan sampel, kemudian mengukur kandungan oksigen terlarut kembali setelah sampel diinkubasi selama 5 hari pada kondisi gelap dan suhu tetap yang sering disebut dengan DO5. Selisih DO $i$ dan DO5 (DOi - DO5) merupakan nilai BOD yang dinyatakan dalam miligram oksigen per liter $(\mathrm{mg} / \mathrm{L})$. Pengukuran oksigen dapat dilakukan secara analitik dengan cara titrasi (metode Winkler, iodometri) atau dengan menggunakan alat yang disebut DO meter yang dilengkapi dengan probe khusus ${ }^{(13,14,15)}$. 


\section{Pengertian COD dan Metode Pengukurannya}

COD atau Chemical Oxygen Demand adalah jumlah oksigen yang diperlukan untuk mengurai seluruh bahan organik yang terkandung dalam air ${ }^{(15)}$. Seluruh bahan organik akan diurai karena pada pengukuran COD ini menggunakan oksidator kuat kalium bikromat pada kondisi asam dan panas dengan katalisator perak sulfat sehingga segala macam bahan organik, baik yang mudah urai maupun yang kompleks dan sulit urai, akan teroksidasi ${ }^{(13,15)}$. Dengan demikian, selisih nilai antara COD dan BOD memberikan gambaran besarnya bahan organik yang sulit urai yang ada di perairan. Nilai COD menggambarkan jumlah total bahan organik yang ada.

Metode pengukuran COD sedikit lebih kompleks, karena menggunakan peralatan khusus reflux, penggunaan asam pekat, pemanasan, dan titrasi ${ }^{(14)}$. Peralatan reflux diperlukan untuk menghindari berkurangnya air sampel karena pemanasan. Prinsipnya pengukuran $\mathrm{COD}$ adalah penambahan sejumlah tertentu kalium bikromat $\left(\mathrm{K}_{2} \mathrm{Cr}_{2} \mathrm{O}_{7}\right)$ sebagai oksidator pada sampel (dengan volume diketahui) yang telah ditambahkan asam pekat dan katalis perak sulfat, kemudian dipanaskan selama beberapa waktu. Selanjutnya, kelebihan kalium bikromat ditera dengan cara titrasi. Dengan demikian kalium bikromat yang terpakai untuk oksidasi bahan organik dalam sampel dapat dihitung dan nilai COD dapat ditentukan ${ }^{(13,15)}$.

\section{BOD dan COD Sebagai Parameter Pencemaran Air dan Baku Mutu Air Limbah}

Nilai BOD dan COD masih menjadi penentu baku mutu limbah air dan pencemaran perairan, baik itu laut, sungai, danau atau waduk selain beberapa parameter kunci lainnya. Dalam Peraturan Menteri lingkungan Hidup Indonesia nomor 5 tahun 2014(17) tentang Baku mutu air limbah ditetapkan baku mutu limbah cair dari 21 jenis kegiatan industri, salah satunya adalah industri batu bara. Parameter Kadar Maksimum Beban Pencemaran Maksimum pada $\mathrm{BOD}_{5}$ dan $\mathrm{COD}$ adalah sebesar 50 dan $100 \mathrm{mg} / \mathrm{l}$. Pada PP no 82 tahun $2001^{(18)}$ tentang Pengelolaan Kualitas Air dan Pengendalian Pencemaran Air ditetapkan batasan maksimal nilai $\mathrm{BOD}_{5}$ dan $\mathrm{COD}$ pada 2 kelas air, yaitu Air Kelas I yaitu air yang peruntukannya untuk air baku air minum, dan atau peruntukan lain yang mempersyaratkan mutu air yang sama dengan kegunaan untuk air baku air minum. Kisaran nilai maksimal $\mathrm{BOD}_{5}$ dan COD yang dipersyaratkan adalah 2 dan 10 $\mathrm{mg} / \mathrm{L}$. Air Kelas II merupakan air dengan keperuntukan untuk prasarana /sarana rekreasi air, pembudidayaan ikan air tawar, peternakan, air untuk mengairi pertamanan. Air di kelas ini ditetapkan kisaran maksimalnya BOD dan COD-nya sebesar 3 dan $25 \mathrm{mg} / \mathrm{L}$.

Parameter BOD dab COD ditetapkan menjadi salah satu parameter penentu baku mutu limbah perairan meskipun ada beberapa hal perlu mendapat perhatian bagi pelaksana di lapangan. Pengukuran BOD memerlukan kecermatan dan ketelitian tertentu. Sampel yang akan dianalisis ada kalanya perlu dilakukan penetralan $\mathrm{pH}$, pengenceran, aerasi, atau penambahan populasi bakteri terlebih dahulu. Pengenceran dan/atau aerasi diperlukan agar masih cukup tersisa oksigen pada hari ke lima.

Pengukuran BOD melibatkan mikroorganisme (bakteri) sebagai pengurai bahan organik, sehingga analisis BOD memerlukan waktu yang lama. Waktu oksidasi biokimia yang dilakukan oleh bakteri ini sangat dipengaruhi oleh suhu perairan. Pada metode standar, suhu yang digunakan pada analisis ini adalah suhu $20^{\circ} \mathrm{C}^{(13)}$. Suhu rata-rata perairan di Indonesia $25-30^{\circ} \mathrm{C}$ sehingga hal ini akan mempengaruhi lamanya inkubasi dan aktivitas bakteri pengurai.

Metode pengukuran COD sedikit lebih kompleks disbanding BOD. Proses pengukuran COD penggunaan asam pekat, pemanasan, dan titrasi dengan memanfaatkan kalium bikromat yang terpakai untuk oksidasi bahan organik dalam sampel. Namun demikian sangat dimungkinkan dapat senyawa kompleks anorganik yang ada di perairan juga ikut teroksidasi dan dihitung menjadi nilai $\mathrm{COD}^{(14)}$. Dengan demikian dalam kasus-kasus tertentu nilai COD mungkin sedikit 'over estimate' untuk gambaran kandungan bahan organik.

\subsection{Tujuan Penelitian}

Penelitian ini bertujuan untuk memaparkan kondisi eksisting nilai BOD, COD dan parameter lainnya dari danau buatan bekas tambang batu bara. Informasi dari kondisi danau yang didapat diharapkan dapat memberikan informasi dan bahan acuan pihak-pihak yang akan merencanakan dan mengelola danau buatan tersebut menjadi sumberdaya alam yang lebih bermanfaat.

\section{BAHAN DAN METODE}

\subsection{Lokasi Studi}

Lokasi penelitian adalah di areal danau paska tambang PT. KPC di Sangatta Kalimantan Timur. Letak Danau Sangatta North adalah terletak pada koordinat $117^{\circ} 27^{\prime} 7,4^{\prime \prime}$ BT-117 $40^{\prime}$ '43,4" BT. Danau ini memiliki kedalaman sekitar 31,68 meter dengan laju aliran rata air yang masuk ke dalam danau adalah sebesar 5,1 liter/detik atau setara dengan $160.833,4 \mathrm{~m}^{3} /$ tahun $^{(19)}$. 


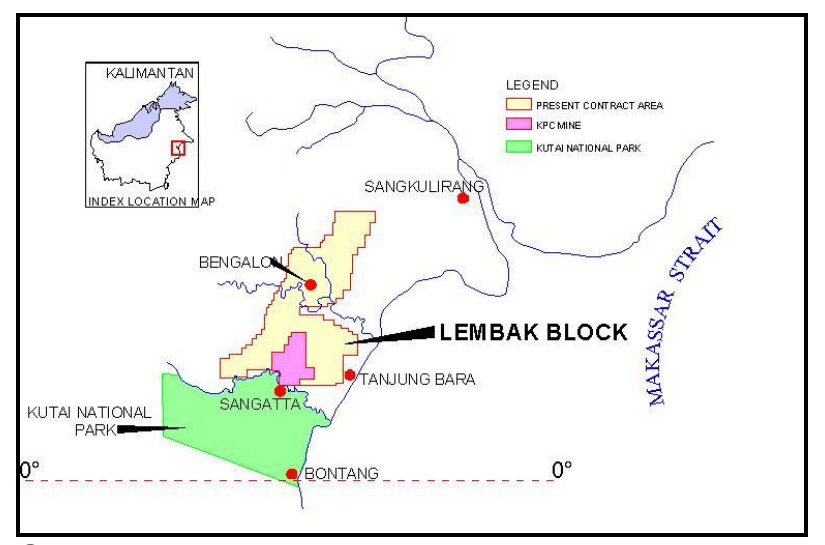

Gambar 1. Lokasi Penelitian

\subsection{Pengumpulan Data Lapangan}

Survei dan pengambilan data dilakukan pada bulan Juli - Desember 2007. Sampel penelitian dibedakan menjadi 2. Sampel dari data pengukuran langsung di lapangan dan sampel yang akan dianalisis di labolatorium. Pengukuran data secara langsung menggunakan probe sensor multi parameter (Chlorotec, type AAQ1183, Alec Electronics) pada beberapa stasiun meliputi parameter kedalaman kolam, temperatur, $\mathrm{pH}$, dan oksigen terlarut (DO). Stasiun pengambilan sampel ditetapkan sebanyak 11 stasiun merata di seluruh permukaan danau. Lokasi stasiun pengambilan sampel disajikan pada gambar di bawah ini.

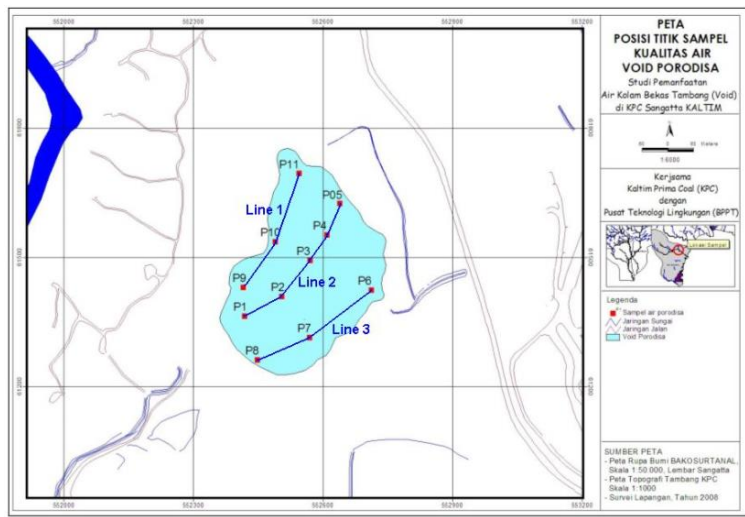

Gambar 2. Lokasi stasiun pengambilan sampel

Pengambilan sampel air untuk dianalisis BOD dan COD dilakukan di 3 stasiun dengan mengunakan Van Dorn pada permukaan perairan (1-2m). Sampel air ini diberi label dan diberi larutan preservasi sesuai kebutuhan sebelum dilakukan analisis di labolatorium. Air sampel yang telah diambil selanjutnya dilakukan analisa sampel. Analisa sampel Biochemical Oxygen Demand (BOD) secara titrimetric dilakukan menurut SNI 6989.72:2009(20). Analisa sampel Chemical Oxygen Demand (COD) secara titrimetric dilakukan menurut SNI 06-2420$1991^{(21)}$
Adapun teknis pengambilan sampel air untuk analisis BOD adalah sebagai berikut: Siapkan jumlah botol DO yang dibutuhkan, setiap lokasi stasiun terdiri dari 2 botol sampel (botol gelap dan botol terang) dan 1 botol kontrol. Melabeli setiap botol dengan jelas tentang nama stasiun, dan perlakukan botol. Mempersiapkan seluruh peralatan menutup botol dan selubung botol sebelum berangkat ke lokasi survei.

Sampling di permukaan, ambil air sampel langsung mengunakan botol DO, usahakan tidak ada gelembung udara dalam botol, bila itu terjadi ulangi pengambilan air sampel. Tutup botol dengan baik bila perlu gunakan isolasi untuk menambah stabilnya penutup botol. 2 botol DO sampel air di perlakukan sebagai botol gelap dan terang, 1 botol sebagai botol DO kontrol segera masukkan reagen kimia winkler untuk memulai proses titrasi. Apabila kondisi lokasi tidak memungkinkan, perlakuan terhadap botol DO kontrol di lapangan hanya memasukkan larutan pengikat oksigen, perlakuan titrasi dapat dilakukan di laboratorium setelah survei selesai(22). Botol ke-2 yang diperlakukan sebagai botol gelap, selubungi botol dengan kertas gelap dan simpan dalam lemari tanpa pencahayaan.

Data dari survei lapangan dan dari analisis BOD dan COD dari 11 stasiun diolah dan ditampilkan secara spasial dalam 3 lintasan vertical profile dan dalam tampilan tabel.

\section{HASIL DAN PEMBAHASAN}

\subsection{Kedalaman Danau}

Survei kedalaman dilakukan dengan melakukan pengukuran sebanyak 106 titik dengan menggunakan alat fish finder dan GPS (Global Positioning System). Hasil pengukuran kedalaman maksimal danau mencapai 35 meter dijumpai di tengah, sementara sekeliling danau relatif dangkal 1-4 meter, tidak dijumpai kedalaman kolam yang ekstrim. Kedalaman maksimum rata-rata hasil pengukuran mencapai 31,68 meter.

\subsection{Oksigen Terlarut}

Hasil pengukuran konsentrasi oksigen terlarut ditampilkan dalam 2 lintasan dengan tampilan 2D cross section. Tampilan grafik ini terdiri atas axis vertikal berupa kedalaman void $(\mathrm{m})$ dan 2 buah axis mendatar, axis mendatar bagian atas berupa posisi stasiun pengambilan sampel dan axis mendatar bagian bawah yang memberikan informasi jarak dari masing masing stasiun dari tepi danau.

Kondisi oksigen terlarut pada lintasan-1 adalah 3-6,8 (4,64 \pm 1.41$) \quad \mathrm{mg} / \mathrm{l}$. Konsentrasi oksigen terlarut dalam kolom air pada lintasan ini terstratifikasi vertikal secara sempurna. Pada kedalaman 3 m konsentrasi oksigen terlarut (DO) masih sekitar $5 \mathrm{mg} / \mathrm{l}$. 


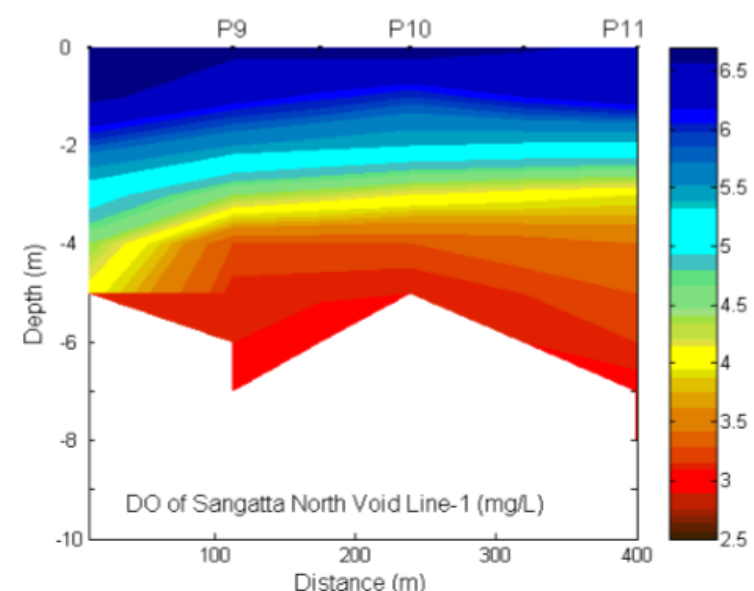

Gambar 3. Distribusi vertikal DO pada lintasan-1

Pada lintasan-2, konsentrasi oksigen terlarut adalah 2,8-6,89 $(4,71 \pm 1.28) \mathrm{mg} / \mathrm{l}$. Pada line ini sampai pada kedalaman $5 \mathrm{~m}$ konsentrasi oksigen terlarut mencapai $6 \mathrm{mg} / \mathrm{l}$.

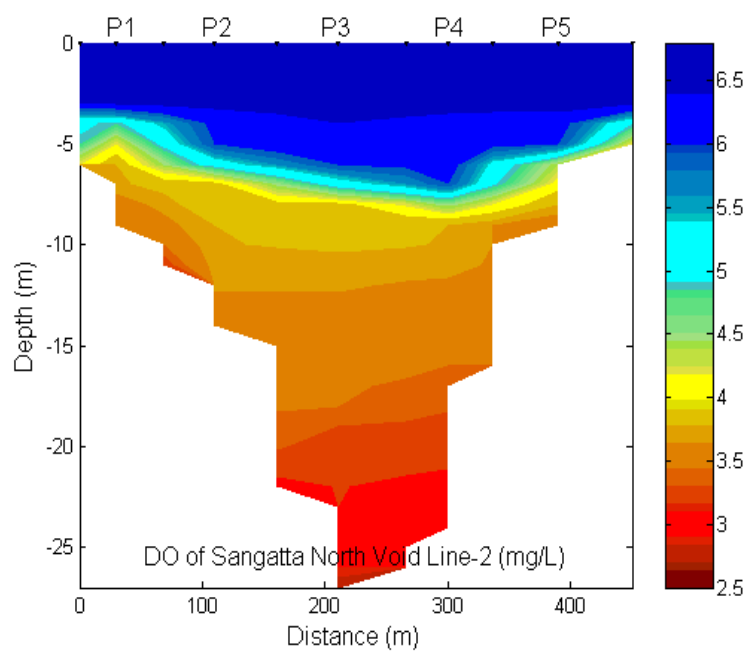

Gambar 4. Distribusi vertikal DO pada lintasan-2

Pada lintasan-3, konsentrasi oksigen terlarut adalah 2,8-6,8 (4,67 \pm 1.47$) \mathrm{mg} / \mathrm{l}$. Kondisinya hampir sama dengan line sebelumnya, sampai pada kedalaman $4 \mathrm{~m}$ konsentrasi oksigen terlarut tercatat $6 \mathrm{mg} / \mathrm{l}$.

Secara umum konsentrasi oksigen terlarut di danau Sangata North ini adalah normal dengan sebaran variasi yang juga stabil sebagaimana perairan danau alami lainnya. Seperti pola distribusi oksigen pada perairan umum, bahwa konsentrasi mulai turun secara bertahap seiring bertambahnya kedalaman. Konsentrasi oksigen ini secara alami bervariasi, tergantung pada suhu, salinitas, turbulensi air dan tekanan atmosfir (23). Konsentrasi oksigen terlarut juga berfluktuasi secara harian (diurnal) dan musiman, tergantung pada perrcampuran (mixing) dan pergerakan (turbulance) massa air, aktivitas fotosintesis, respirasi dan limbah (effluent) yang masuk ke dalam badan air tersebut.

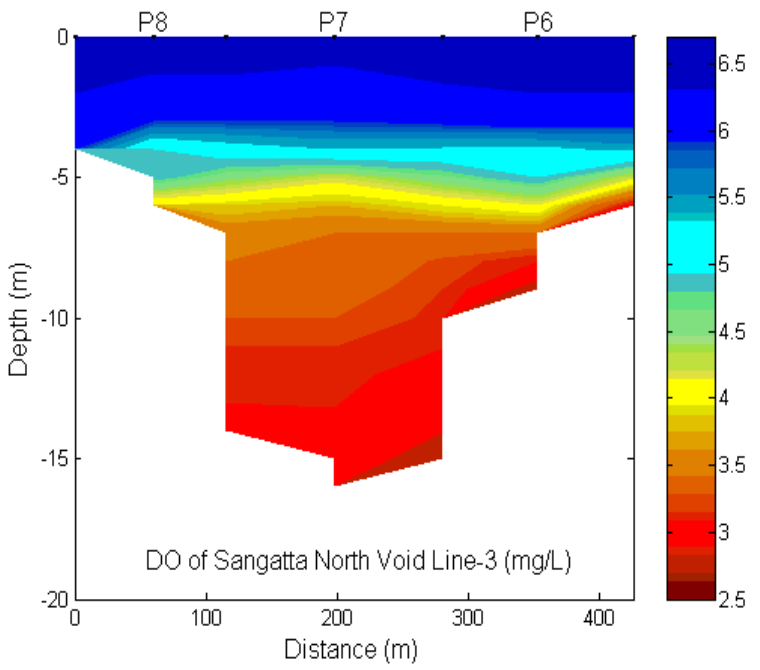

Gambar 5. Distribusi vertikal DO pada lintasan-3

Sumber oksigen terlarut dapat berasal dari difusi oksigen yang terbentuk di atmosfir (35\%), dan sumbangan yang terbesar berasal dari aktivitas fotosintesis tumbuhan air dan fitoplankton dalam badan air ${ }^{(24)}$.

\subsection{Keasaman Air (pH)}

Hasil pengukuran rata-rata $\mathrm{pH}$ air danau Sangatta North dalam lintasan-1 dan lintasan-2 dapat dilihat masing-masing seperti pada Gambar 6 dan 7.

Tingkat keasaman $(\mathrm{pH})$ pada lintasan-1 berkisar antara $6-7,8(7,1 \pm 0,55), \mathrm{pH}$ air di kolam Sangatta North pada line-2 adalah berkisar antara 5,98-7,8 $(6,79 \pm 0,56)$. pH air danau sampai kedalaman $6 \mathrm{~m}$ berkisar antara 6,5 sampai dengan 7,8 . Hal ini menunjukkan kondisi perairan yang normal. Berdasarkan hasil pengukuran dapat dilihat bahwa $\mathrm{pH}$ air danau 5,95 pada tengah danau.

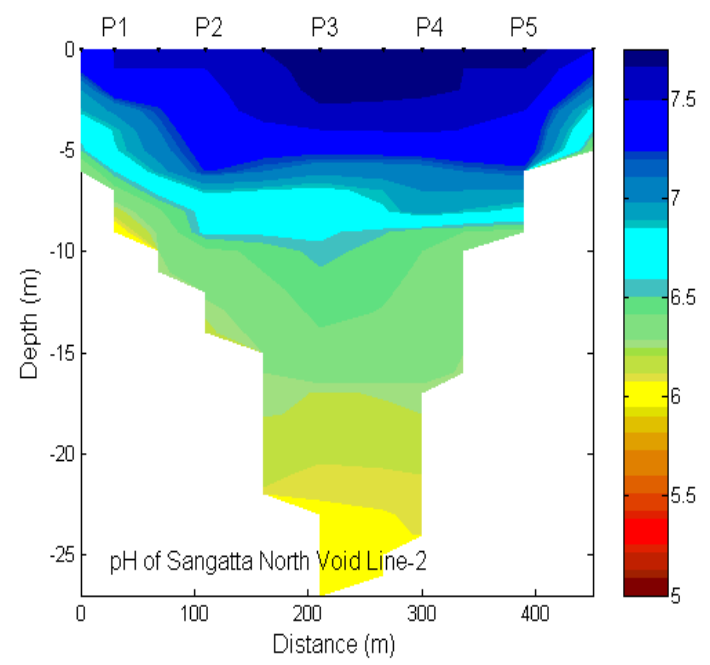

Gambar 6. Distribusi vertikal pH pada lintasan-1 
Nilai kisaran $\mathrm{pH}$ mempengaruhi proses biologi dan kimia danau. Nilai $\mathrm{pH}$ pada badan air dapat menekan kemampuan reproduksi organisme tententu dan dapat menyebabkan subtansi beracun menjadi lebih siap diambil tanaman dan hewan air. Nilai $\mathrm{pH}$ yang rendah $(4,5-5)$ dalam waktu yang lama akan menyebabkan beberapa hal negatif pada perairan antara lain penurunan nilai keanekaragaman dan komposisi plankton, perifiton dan bentos semakin besar, penurunan kelimpahan total biomassa dan produktivitas zooplankton dan benthos semakin besar dan terjadi penghambatan proses nitrifikasi ${ }^{(24)}$.

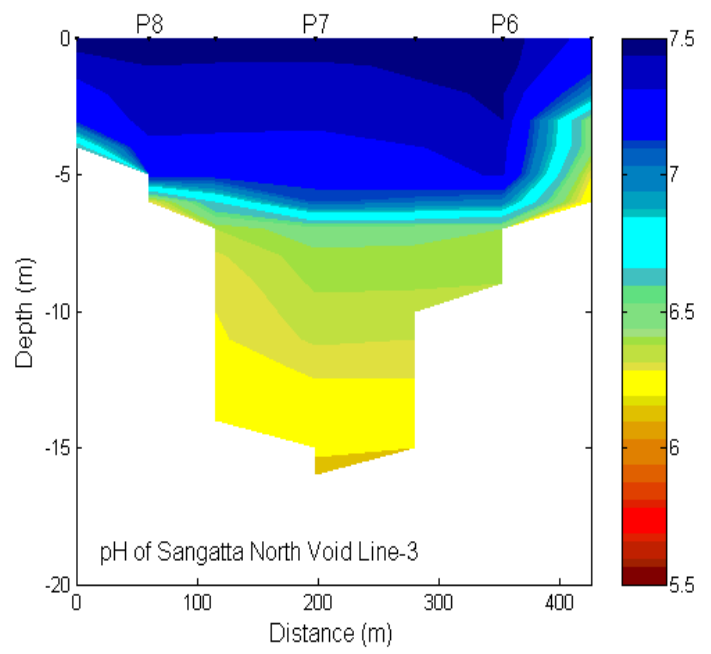

Gambar 7. Distribusi vertikal pH pada lintasan-3

Mengacu pada Peraturan Pemerintah PP 82 tahun 2001 tentang kualitas air, kisaran $\mathrm{pH}$ pada Danau Sangatta North masih dalam batas yang menunjang kehidupan organisme tropis. Yang perlu diperhatikan adalah upaya menjaga nilai $\mathrm{pH}$ danau agar tidak meningkat ke arah kondisi sangat basa, sebab akan dapat mendorong kehidupan mikroba patogen dibanding dalam kondisi $\mathrm{pH}$ asam.

\subsection{BOD dan COD}

Hasil analisis sampel dari BOD dan COD pada beberapa stasiun di Danau Sangatta North disajikan dalam Tabel 1.

Tabel 1. Hasil pengukuran BOD, COD dan Delta BOD-COD pada stasiun di Danau Sangatta North

\begin{tabular}{|c|c|c|c|}
\hline Stasiun & BOD $(\mathrm{ppm})$ & $\mathrm{COD}(\mathrm{ppm})$ & $\Delta(\mathrm{ppm})$ \\
\hline P1 & 2 & 5,57 & 3,57 \\
\hline P3 & 2 & 5,57 & 3,57 \\
\hline P5 & 2 & 5,57 & 3,57 \\
\hline
\end{tabular}

Dari tabel terlihat bahwa nilai rata-rata dari BOD dan COD adalah 2,0 dan $5,57 \mathrm{mg} / \mathrm{l}$. Nilai BOD dan COD pada stasiun P1, P3 dan P5 menunjukkan nilai yang di batas batas nilai baku mutu untuk katagori air kelas II dengan batas nilai
$3 \mathrm{mg} / \mathrm{l}$ untuk nilai BOD dan $25 \mathrm{mg} / \mathrm{l}$ untuk nilai COD.

Mengacu pada hasil pengukuran BOD dan COD dari peneliti lain ${ }^{(8,10)}$ pada lokasi yang sama, menyatakan bahwa BOD dan COD adalah 3,58 \pm

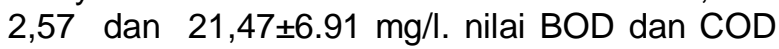
yang relatif tinggi terjadi pada stasiun pengambilan sekitar P1 yakni 7,13 dan 18,15 $\mathrm{mg} / \mathrm{l}$. Sedangkan di stasiun lain menunjukkan nilai yang di bawah batas nilai baku mutu untuk katagori air kelas II dengan batas nilai $3 \mathrm{mg} / \mathrm{l}$ untuk nilai BOD dan $25 \mathrm{mg} / \mathrm{l}$ untuk nilai COD. Tingginya nilai BOD dan COD pada ke-1 stasiun ini dimungkinkan karena lokasi stasiun tersebut berada dekat dengan inlet danau yang secara berkala menerima suplai air dari saluran pembuangan air kawasan pertambangan dan pemukiman karyawan ${ }^{(8,19)}$. Secara umum, kualitas air Danau Sangatta North cukup baik untuk dapat dimanfaatkan untuk kepentingan sarana rekreasi air, pembudidayaan ikan air tawar, peternakan, pengairan pertanian dan peruntukkan lain yang mempersyaratkan mutu air pada kelas $\|^{(8,10)}$. Tingginya nilai $B O D$ dan $C O D$ pada beberapa stasiun dimungkinkan akan dapat dinetralisir oleh kemampuan badan air sendiri dalam mendekomposisi bahan organik yang masuk ke danau.

\subsection{Pembahasan Umum}

Nilai rata-rata BOD adalah $3,58 \mathrm{mg} / \mathrm{l}$ lebih tinggi dari nilai batas baku mutu air klas II (3 $\mathrm{mg} / \mathrm{l})$. Hal ini dikarenakan masukan input air yang mengandung bahan organik tinggi-dari aktifitas pertambangan dan perumahan. Nilai BOD ini dimungkinkan akan menurun karena aktivitas dekomposisi dari badan air danau sendiri. Kemampuan dekomposisi badan air terlihat dari nilai BOD pada stasiun lain yang relatif rendah.

Kemampuan dekomposisi yang tinggi dari badan air danau dalam mengurai bahan organik yang masuk ditunjang oleh kondisi kualitas air seperti $\mathrm{pH}$, dan oksigen terlarut yang menunjukkan nilai yang relative baik. Nilai $\mathrm{pH}$ danau pada permukaan hingga kedalaman $6 \mathrm{~m}$ sekitar $6,5-7,8$. Nilai $\mathrm{pH}$ ini sangat menunjang optimalisasi proses dekomposisi bahan organik oleh bakteri( ${ }^{24)}$. Keasaman air $(\mathrm{pH})$ mempengaruhi tingkat kehidupan jasad renik. Organisme akuatik lebih menyukai $\mathrm{pH}$ mendekati $\mathrm{pH}$ netral, yakni sekitar $7^{(26)}$. Dengan populasi mikroorganisme yang optimal maka kinerja dekomposisi juga akan berjalan optimal.

Hasil pengukuran kandungan oksigen terlarut (DO) pada setiap stasiunnya menujukkan hasil di atas Baku Mutu Air yaitu $\geq 4 \mathrm{mg} / \mathrm{l}$. Nilai DO rendah hanya terjadi pada badan danau dengan kedalaman $15 \mathrm{~m}$ hingga dasar danau. Kondisi danau dilihat dari kadar oksigen 
terlarutnya termasuk dalam kategori tidak tercemar dimana klasifikasi perairan menurut oksigen terlarut adalah sebagai berikut: tidak tercemar ( $\geq 6.5 \mathrm{mg} / \mathrm{l})$, tercemar sedang (4,5 $6,5 \mathrm{mg} / \mathrm{l})$ dan tercemar berat $(<2.0 \mathrm{mg} / \mathrm{l})^{(27)}$.

Dari hasil pengukuran menunjukkan pola bahwa nilai COD selalu lebih besar (2-4 kali) dari BOD. Tingginya nilai COD secara umum dibanding BOD kemungkinan disebabkan karena nilai BOD hanya terpengaruh pada jumlah TSS dan juga zat organik yang ada dalam air saja, sedangkan nilai COD dipengaruhi oleh seluruh pengotor air yang meliputi zat organik, mineral bervalensi rendah, dan senyawa kimia lain yang reaktif dengan oksigen (oxygen scavanger).

Mengacu pada Peraturan Menteri Lingkungan Hidup Indonesia nomor 5 tahun 2014, parameter BOD dan COD secara bersama sama selalu dipakai sebagai parameter baku mutu air limbah melengkapi parameter kunci lainnya. BOD dan COD bukan merupakan parameter kunci, namun keberadaannya dapat menguatkan parameter sebagai penentu kondisi kualitas suatu perairan. Dalam suatu kasus analisis, misalnya nilai BOD dan COD menunjukkan nilai yang normal atau memenuhi baku mutu, maka masih belum dapat disimpulkan bahwa perairan tersebut tidak terjadi pencemaran, bila parameter kunci lainnya tidak diketahui. Hal ini dikarenakan misal bila dalam perairan terdapat bahan-bahan toksik (beracun) atau senyawa logam berat misalnya ${ }^{(14,26)}$, nilai BOD bisa jadi menunjukkan nilai rendah atau masih memenuhi baku mutu, pada hal dalam air atau perairan tersebut terkandung bahan beracun atau air telah tercemar. Sebaliknya, bila nilai BOD dan COD telah cukup tinggi dan melebihi baku mutu, maka sudah dapat diduga ada indikasi pencemaran bahan organik.

Akhirnya dapat dinyatakan bahwa meskipun Aplikasi BOD dan COD banyak mengalami kendala teknis di lapangan, BOD dan COD tetap digunakan sampai sekarang. Hal ini karena beberapa alasan, terutama dalam hubungannya dengan pengolahan air limbah, yaitu

a. BOD penting untuk mengetahui perkiraan jumlah oksigen yang akan diperlukan untuk menstabilkan bahan organik yang ada secara biologi;

b. untuk mengetahui ukuran fasilitas unit pengolahan limbah;

c. untuk mengukur efisiensi suatu proses perlakuan dalam pengolahan limbah; dan

d. untuk mengetahui kesesuaiannya dengan batasan yang diperbolehkan bagi pembuangan air limbah ${ }^{(13)}$.

\section{KESIMPULAN}

Parameter BOD-COD tetap digunakan sebagai parameter penentu kualitas perairan bersama parameter lainnya karena peranannya yang penting dalam menentukan kualitas suatu perairan. Nilai BOD di perairan umum cenderung memiliki nilai yang lebih kecil dibanding COD karena perbedaan cakupan pengaruh pencemar di perairan.

Nilai BOD, COD danau Sangatta Notrh berkisar 2 dan $5,57 \mathrm{mg} / \mathrm{l}$. Kisaran nilai parameter relatif stabil karena ditunjang oleh nilai parameter DO dan $\mathrm{pH}$ yang relatif baik. Nilai DO sekitar 2,8$6,89(4,71 \pm 1.28) \mathrm{mg} / \mathrm{l}$ dan nilai $\mathrm{pH}$ sekitar $6-7,8$ $(7,1 \pm 0,55)$. Secara umum kualitas air pada danau Sangatta North dalam kondisi stabil dan normal sehingga dapat dimanfaatkan untuk kepentingan sarana rekreasi air, pembudidayaan ikan air tawar, peternakan, pengairan pertanian dan peruntukan lain yang mempersyaratkan mutu air pada kelas II.

\section{PERSANTUNAN}

Kepada PT. KPC Prima Coal atas bantuan pembiayaan penelitian bagi penulis. Penghargaan yang tinggi penulis sampaikan kepada Tim Penelitian Danau Buatan KPC atas kerjasamanya dalam kegiatan survei, analisis lab hingga penyusunan dan revisi makalah ini.

\section{DAFTAR PUSTAKA}

1. Dewan Energi Nasional. (2016). Outlook Energi Indonesia 2016. Sekretaris Jendral Dewan Energi Nasional, 137 p.

2. https://bp.com/content/dam/bp/en/corporate/p df/energy-economics/statistical-Review-

2017/bp-statistical-review-of-world-energy2017-full-report.pdf. Diunduh 10 September 2017 jam 20.05 Wib.

3. Gaikwad, R.W., Gupta, D.V. (2008). Review on removal of heavy metals from acid mine drainage. Appl. Ecol. Environ. Res. 6 (3), 8198.

4. Bhattacharya, J. Islam, M., Cheong, Y.W. (2006). Microbial growth and action: implications for passive bioremediation of acid mine drainage. Mine Water Environ. 25 (4), 233-240.

5. J.K. Bwapwa, AT. Jaiyeola, R Chetty. (2017). Bioremediation of Acid mine drainage using algae strains: A riview South African Journal of Chemical Engeneering, (24), 60-70.

6. Miller, D.J., Semmens, K.J., Viadero Jr., R.C., \& Tierney, A.E. (2004). The resource potential of mining discharge water for aquaculture. World Aquaculture, 35: 57-59.

7. J. Skosen, A. Rose, G. Geidel, J. Foremen, R. Evans, W. Hellier. (1998). Handbook of Technologies for Avoidance and Remediation of Acid Mine Drainage. The National Mine 
Land Reclamation Center. West Virginia University. Pp 123.

8. Maidie A., Udayana D., Isriansyah, Almady IF., Susanto A., Sukarti K., Sulistiawaty, Manege I., Tular E. (2010). Pemanfaatan Kolam Pengendap Tambang Baubara untuk Budidaya Ikan Lokal dalam Keramba. J. Ris. Akuakultur, .5(3), 437-448.

9. Azwir. (2006). Analisa Pencemaran Air Sungai Tapung Kiri oleh Limbah Industri Kelapa Sawit PT. Peputra Masterindo di Kabupaten Kampar. Semarang: Program Magister IImu Lingkungan Program Pasca Sarjana Undip Semarang.

10. Pagoray H., and Ghitarina. (2016). Characteristics of Water Quality of Coal PostMining Pool Which Used for Fish Cultivation. ZIRAA'AH, 41(2), 276-284.

11. Stumm, W., and J.J. Morgan. (1996). Aquatic chemistry: an introduction emphasizing chemical equilibria in natural waters. 3rd Ed. John Wiley and Sons. New York.

12. Mazidah, R., A. Mulyadi, S. Nasution. (2013). Tingkat Pencemaran Perairan Danau Buatan Pekanbaru Ditinjau dari Parameter Fisika, Kimia dan Biolobi. Jurna Kajian Lingkungan (01), 01: 11-22.

13. Metcalf \& Eddy. (1991). Wastewater Engineering: treatment, disposal, reuse.3rd ed. (Revised by: G. Tchobanoglous and F.L. Burton). McGraw-Hill, Inc. New York, Singapore. $1334 \mathrm{p}$.

14. Umaly, R.C. \& L.A. Cuvin. (1988). Limnology: Laboratory and field guide, Physico-chemical factors, Biological factors. National Book Store, Inc. Publishers. Metro Manila. $322 \mathrm{p}$.

15. Boyd, C.E. (1990). Water quality in ponds for aquaculture. Alabama Agricultural Experiment Station, Auburn University, Alabama. 482p.

16. Mays, L.W. (1996). Water resources handbook. McGraw-Hill.New York. p: 827.

17. Peraturan Menteri lingkungan Hidup Indonesia nomor 5 tahun 2014 tentang Baku mutu air limbah.

18. Peraturan Pemerintah no 82 tahun 2001 tentang Pengelolaan Kualitas Air dan Pengendalian Pencemaran Air
19. Anonimous. (2006). Laporan Pengukuran Kedalaman dan Kualitas Air di Porodisa Pond (WQ61A) November 2006. PT Kaltim Prima Coal. 9 hal.

20. SNI 6989.72:2009. Air dan Limbah - Bagian 72. Cara uji kebutuhan oksigen biokimia (Biochemical Oxygen Demand/BOD. Badan stadarisasi Nasional. 28p.

21. SNI 06.2420:1991. Metode pengujian kelindian dalam air degan titrimetri. Badan stadarisasi Nasional. 22p.

22. David, R., Teichert, C., Bartho lomew W. (1993). Influence of daylight and incubation interval on water column respiration in tropical fish ponds. Hydrobiologia, 250 (3), 159-165.

23. Jeffries, M., dan D. Mills. (1996). Freshwater Ecology, Principles and Applications. John Wiley and Sons Chicester. UK.

24. Novotny, V. and H. Olem. (1994). Water Quality, Prevention, Indentification and Management of diffuse Pollution. Van Nostrans Reinhold, New York. 1054p.

25. Siahaan, R. (2011). Kualitas Air Sungai Cisadane Jawa Barat Banten. Jurnal IImiah Sains 11 (2): $268-273$.

26. Effendi, H. (2000). Telaah Kualitas Air bagi Pengelolaan Sumber Daya dan Lingkungan Perairan. Fakultas Perikanan dan IImu Kelautan IPB. Bogor.

27. Ardi. (2002). Pemanfaatan Makrozoobentos Sebagai Indikator Kualitas Perairan Pesisir. Bogor: Program Pasca Sarjana IPB Bogor

28. Ramanand MB., Roopali, Hiremath and Kulkarni VR. (2003). Correlation between BOD, COD and TOC. Jr. of Industrial Pollution Control, 19(2), 187 -191.

29. Udeni AH., Gunawardena HD., Amaramali YN. (1993). Correlation between BOD dan COD for different Industrial Waste Waters. J. Natn.Sci. Coun. 21(2), 259-266.

30. Apha. (1989). Standard methods for the examination of waters and wastewater. 17th ed. American Public Health Association, American Water Works Association, Water Pollution Control Federation. Washington, D.C. $1467 p$ 